\title{
Extensão e Emancipação no contexto do Projeto Olhares Sul Riograndenses da Educação de Jovens e Adultos
}

\author{
Vilmar Alves Pereira ${ }^{1}$ \\ Luciane Oliveira Lemos ${ }^{2}$
}

Este texto objetiva apresentar uma experiência formativa ocorrida no contexto do Projeto de Extensão Olhares Sul Riograndenses da Educação de Jovens e Adultos com 180 professores de escola pública no período de maio de 2013 a janeiro de 2015. Este projeto foi desenvolvido em pareceria entre a FURG, a Secretaria Municipal da Educação do Rio Grande e a $18^{a}$ Coordenadoria de Educação do Estado do Rio Grande do Sul, no contexto de formação de professores nos municípios de Rio Grande, São José do Norte, Santa Vitória e Chuí no extremo sul do país. Em cada pólo tivemos encontros mensais no período da noite. A proposta metodológica e epistemológica do curso, baseou-se na perspectiva dialética de horizonte materialista histórico e freiriano. Aqui apresentaremos, um recorte sobre como trabalhamos as questões referentes ao compromisso político do educador associado às concepções de educação. A Perspectiva crítica freiriana é orientadora de toda essa experiência. Ficou reforçado que a Educação Problematizadora contribui nos processos formativos e emancipatórios na EJA.

Palavras-chave: Extensão, Emancipação, EJA.

\section{Extension And Emancipation In The Context Of The Project Looks South Of Rio Grande Adult Education}

This text aims to present a formative experience that occurred in the context of the Extension Project Olhares Sul Riograndenses of Education of Youths and Adults with 180 public school teachers from May 2013 to January 2015. This project was developed in partnership between FURG, The Municipal Secretary of Education of Rio Grande and the 18th Coordination of Education of the State of Rio Grande do Sul, in the context of teacher training in the municipalities of Rio Grande, São José do Norte, Santa Vitória and Chuí in the extreme south of the country. In each polo we had monthly meetings in the evening. The methodological proposal is epistemological of the course, was based on the dialectical perspective of historical and Freirian materialist horizon. Here we present, a clipping about how we work on issues related to the political commitment of the educator associated with conceptions of education. Freire's Critical Perspective guides this whole experience. It was reinforced that Problematic Education contributes to the formative and emancipatory processes in the EJA.

Keywords: Extension, Emancipation, EJA.

\footnotetext{
${ }^{1}$ Professor e pesquisador Nos programas de Pós Graduação (PPGEA e PPGEDU) da FURG. Coordenador do Programa de Auxílio Ao Ingresso nos Ensinos Técnico e Superior da PAIETS-FURG. Tutor do Grupo PET conexões de saberes da Educação Popular e Saberes Acadêmicos. Coordenador do Projeto de Extensão Olhares Sul Riograndenses Da Educação de Jovens e Adultos.

${ }^{2}$ Historiadora pela Universidade Federal do Rio Grande. Educadora no Projeto Olhares Sul Rio grandense da Educação de Jovens e Adultos. Estudante do quarto ano de Licenciatura em História pela FURG.
} 


\section{INTRODUÇÃO}

Conforme Romão (2006), a Educação de Jovens e Adultos no Brasil foi marcada pela concepção de "erradicar" o analfabetismo como se fosse uma doença, uma espécie de "praga" ou "mancha" a ser eliminada. Assim, entre 1946 a 1958, foram realizadas campanhas nacionais, no âmbito da política oficial e, entre os anos de 1958 e 1964 assistiu-se à implantação do Plano Nacional de Alfabetização de Adultos. Apenas recentemente este assunto passa a ter um tratamento diferenciado. De certa forma, o que fica evidente nesse horizonte, é o espaço que a referida modalidade ganha nas políticas educacionais. Na sua trajetória, a EJA sempre esteve voltada para uma camada marginalizada com experiências pretéritas de exclusão social. Nesse sentido, discutir EJA, pressupõe em primeiro lugar o reconhecimento que estamos discutindo modelos de sociedade que precedem a busca de utopias e esperanças de uma educação emancipadora. Assim, assistimos e presenciamos no Brasil, um cenário em que a formação em EJA é apresentada muitas vezes, como ações esporádicas a partir de uma perspectiva messiânica e salvacionista, sem passar pelos momentos de problematização, onde se discute de fato, quais são os objetivos dessa formação.

\section{Das alternativas: horizonte metodológico}

Mediante a esse cenário, o Projeto Olhares surge de uma procura, no final de 2012, da $18^{a}$ Coordenadoria Regional de Educação vinculada a Secretaria Estadual de Educação do Rio Grande do Sul e da Secretaria Municipal de Rio Grande. Nela foi solicitado ao Grupo de Educação Popular vinculado ao Programa de Auxílio ao Ingresso aos Ensinos Técnico e Superior PAIETS -FURG a possibilidade de oferecermos atividades de formação para EJA, em especial, para professoras da Educação básica dos referidos municípios. A exigência é pudéssemos trabalhar com a temática da avaliação. Cabe ressaltar, que nosso grupo é composto por educadores populares que atuam diretamente em contextos de Educação Popular nos Pré-Universitários Populares, no contexto do Projeto de Educação Para Pescadores (na modalidade EJA) e, mais recentemente, em cenários de atividades com prisioneiros e população LGBT. Para essa atividade, contamos 16 educadores(as) tendo também na equipe 4 (quatro) Professoras da Educação Básica sendo, duas vinculadas ao município (Equipe da Secretária Municipal da Educação) e duas ao estado (18 ${ }^{\text {a }}$ Coordenadoria Regional da Educação).

Revista Extensão em Foco, no 13, Jan/ Jul (2017) p. 23 - 35. 
Em resposta a esse convite, os integrantes do PAIETS se dispuseram a pensar coletivamente um curso, com um encontro mensal em cada um dos Núcleos, sendo dois núcleos em Rio Grande, um em São José do Norte e outro em Santa Vitória com Professores(as) também do Chuí. Todos os principais encontros ocorreram em escolas públicas próximo ou nos contextos de atuação dos educadores(as). O planejamento partia da tematica mensal da concepção de educação até no final do curso podermos discutir a tão desejada avaliação na EJA. Enquanto equipe, nos reuníamos semanalmente para avaliar o encontro anterior e planejar o próximo.

Contudo, tínhamos enquanto educadores(as), a compreensão da premissa que não se discute avaliação sem discutir concepção de educação e por decorrência modelos de sociedade. Como o nosso objetivo era justamente provocar a reflexão sobre modelos de sociedade, acordamos que o primeiro encontro dessa formação seria no dia 13 de maio de 2013. Nessa ocasião, esteve na FURG Frei David da rede EDUCAFRO discutindo a seguinte temática: Universidade, Ações Afirmativas e Projeto de Nação. O objetivo dessa atividade integrada com a comunidade em geral que veio assistir essa palestra, era para mostrar que as raízes da EJA são comuns ao modelo de sociedade e de escola que construímos, ao longo de muitos anos no Brasil. Esse foi nosso primeiro encontro, juntamente com mais de 600 pessoas no auditório do Centro Integrado de Desenvolvimento Costeiro (Cidec-Sul). Os participantes dessa Aula Magna eram estudantes ingressantes na Universidade após a primeira seleção pela política de cotas, a partir da Lei de Reserva de Vagas 12.711de 29 de agosto de 2012, integrantes de diversos movimentos sociais de Rio Grande Camaquã e Pelotas (RS), em especial do Movimento Negro e Professores(as) da Educação Básica da Rede Pública. Interessante ressaltar, que nem todos os educadores da EJA participaram dessa atividade. Alguns até não conseguiram ver relação entre seus fazeres na EJA e esse convite para o encontro oriundo das referidas instituições. Compreendemos que isso não consiste em algo casual mas, possui profundas raízes históricas.

De acordo com Miranda (2016) ao longo da história a EJA se constitui principalmente em classes de alfabetização. Motivação esta surge por dois fatores: primeiro, pela necessidade de aprender a escrever o nome, facilitando o processo de obtenção de documentação; segundo, pelas mudanças na legislação. $\mathrm{O}$ autor considera que existem muitas críticas quanto ao modo com que a EJA é desenvolvida. Tal modalidade de ensino não foi criada para desviar o aluno da escola regular, pelo contrário, foi idealizado para trazer de volta aos espaços 
escolares todos aqueles que não tiveram oportunidade de estudar na idade correta. Sendo assim, faz-se necessário um resgate da respeitabilidade da mesma, buscando ensino de qualidade que possibilite reverter à ideia de que o EJA é uma modalidade de oferta de segunda categoria.

Contudo a realidade da EJA, embora em expansão nas séries finais do Ensino Fundamental e Médio ainda é preocupante. Ainda se faz necessário a criação de programas e projetos, de modo a minimizar os altos índices de analfabetos ou sujeitos que ainda não concluíram o Ensino Fundamental e Médio.

O não comparecimento no primeiro encontro não se repetiu no segundo, que ocorreu no mesmo mês em 29 de maio de 2013, onde começamos aqueles momentos de identificação a partir de algumas provocações para mais de 180 professores(as) da EJA. Lá estavam atentos, buscando respostas para as inquietações cotidianas. São eles, homens e mulheres de grande bravura e profissionalismo que na sua maioria estão cumprindo seu terceiro turno de atividades com jovens e adultos com perfis muito diferenciados daqueles antes imaginados e vivenciados. Eles também alegaram na sua maioria e denunciaram a fragilidade dos cursos de licenciaturas nos quais quando se formaram a temática EJA estava na invisibilidade nos currículos. Só recentemente essa modalidade ganha maior reconhecimento. Traziam a denúncia de poucos espaços para formação na EJA.

Quando almejavam que apresentaríamos soluções para suas lutas cotidianas, começamos ao contrário apresentando provocações. Em geral, essas provocações foram no sentido de politizar o debate. Assim, naquela ocasião questionamos: porque as lutas do movimento docente mesmo que despertem simpatias localizadas e pontuais, não conseguem a mobilização generalizada da opinião pública a seu favor? Não construímos ou perdemos a capacidade de articulação com a sociedade? Não será por que nos omitimos em relação a inclusão dos excluídos, no sistema educacional? Quem sou eu professor ou educador? Que postura assumo? Sou um profissional da educação? Profissional de ensino? Somos educadores ou nos tornamos educadores? Qual é a relação entre a minha profissão e a política? Que postura assumo nesse contexto? Qual é a relação entre a minha formação e minha função exercida? Do que depende a formação do educador? No meu jeito de ser professor existe um educador? Salientamos que esse foi um momento de exposição reflexiva, pois nosso objetivo era sim, colocar as vivências da EJA sob a boa suspeita e reflexão crítica.

Revista Extensão em Foco, no 13, Jan/ Jul (2017) p. 23 - 35. 
Provocando ainda mais os educadores, apresentamos a perspectiva de Romão que salienta que a dimensão política do trabalho do professor se dá em três direções: "para o sistema, para a própria categoria para a comunidade, corporificada diretamente nos educandos" (ROMÃO, 2006, p.65).

Aproximamos essa necessidade aos dados o Pnad onde afirma que o Brasil tem 2,4 milhões de jovens analfabetos. Considera ainda que alarmante número de 15,5 milhões de brasileiros acima de 10 anos que não sabem ler nem escrever, $15 \%$ têm menos de 30 anos. A maior concentração está no Nordeste, onde estão $65 \%$ dos jovens analfabetos do país.

Reconhecendo a necessidade de enfrentamento desse quadro apresentamos aos docentes da EJA a reflexão sobre o nosso compromisso e a nossa postura política no contexto da EJA:

Pela educação, queremos mudar o mundo, a começar pela sala de aula, pois as grandes transformações não se dão apenas como resultantes dos grandes gestos, mas de iniciativas cotidianas, simples e persistentes. Portanto não há excludência entre o projeto pessoal e o coletivo: ambos se complementam dialeticamente" (ROMÃO, 2006, p.65).

Mediante a essa provocação, sugerimos que pudéssemos assumir a pedagogia da indignação em relação ao sistema; a mobilização da categoria, visando ultrapassarmos a "síndrome do metalúrgico" de apenas nos lamentarmos e, numa outra dimensão, buscarmos criticamente alternativas viáveis. Foi justamente nessa etapa que emergiram algumas questões trazidas pelos educadores(as): mas como politizar o educador? Nos planos de cursos? Formação continuada? Também, no entanto sugerimos que devêssemos repensar as nossas práticas na EJA e nos aproximarmos do contexto e do mundo da vida do educando e considerarmos os pilares do conhecimento, didática, relacionamento e avaliação.

Até aqui estava tudo bem! nesse momento, havíamos criado sim um espaço para que pudéssemos chegar onde almejávamos: discutir as concepções de educação. Poderíamos ter feito a opção na ocasião em fazer um vôo pelas teorias da educação, no entanto optamos em discutirmos a centralidade e a relevância da perspectiva freiriana na Pedagogia do Oprimido quando Freire (2011), nos apresenta a concepção de Educação Bancária e a Educação Problematizadora. Entendemos que ali aparece de forma mais explícita o horizonte pedagógico e político freiriano.

Revista Extensão em Foco, nº 13, Jan/ Jul (2017) p. 23 - 35. 
Procurando situar a partir da p. 79 da referida obra em que consiste a Concepção de Pedagogia Bancária, ele parte de uma análise das relações educador-educando, na escola. Segundo ele em qualquer de seus níveis (ou fora dela), apresentam um caráter especial e marcante - o de serem relações fundamentalmente narradoras, dissertadoras. Essa

dimensão narrativa da pedagogia bancária para Freire considera a realidade,

como algo parado, estático, compartimentado e bem-comportado, quando não falar ou dissertar sobre algo completamente alheio à experiência existencial dos educandos, vem sendo, realmente, a suprema inquietação desta educação. E nesse contexto os conteúdos que são retalhos da realidade desconectados da totalidade em que se engendram e em cuja visão ganhariam significação (FREIRE, 2011, p.79).

Outro aspecto marcante de tal pedagogia é a figura do narrador como condutor dos seus educandos transformando-os todos em:

em "vasilhas", em recipientes a serem "enchido" pelo educador (...) Em lugar de comunicar-se, o educador faz "comunicados" e depósitos que os educando, meras incidências, recebem pacientemente, memorizam e repetem, guardá-los e arquivá-los (FREIRE 2011, p.80-81).

Freire denuncia essa dimensão bancária e arquivista da educação pelo fato do professor não permitir, nem a criatividade nem a transformação e o reconhecimento de saberes. De certa forma, o que ocorre nesse processo é um profundo processo de alienação: "Os educandos alienados, reconhecem em sua ignorância a razão da existência do educador, mas não chegam, nem sequer a descobrir-se educadores do educado" (FREIRE (2011, p.81)

Nessa definição de papéis vemos que:

- o educador é o que educa; os educando, os que são educados;

- o educador é o que sabe; os educando, os que não sabem;

- o educador é o que pensa; os educando, os pensados;

- o educador é o que diz a palavra; os educandos, os que escutam docilmente;

- o educador é o que disciplina; os educandos, os disciplinados;

- o educador é o que opta e prescreve sua opção; os educandos, os que seguem a prescrição;

- o educador é o que atua; os educandos, os que tem a ilusão de que atuam, na atuação do educador;

- o educador escolhe o conteúdo programático; os educandos, jamais ouvidos nesta escolha, se acomodam a ele (FREIRE (2011, p.82). 
Freire prossegue na Pedagogia do Oprimido, dedicando as próximas páginas ao delineamento da ausência de pensamento crítico dos educandos nessa perspectiva e consequente na perda da dimensão transformadora. Também aponta para a não assunção da condição de sujeitos, pois seu fundamente é o reforço da condição do opressor. "A visão "bancária" anula o poder criador dos educandos ou o minimiza, estimulando sua ingenuidade e não sua criticidade, satisfaz aos interesses dos opressores"(FREIRE (2011, p.83).

Dessa forma, conforme Freire, os oprimidos como decorrência desse processo, são considerados como uma patologia de uma sociedade sã, sem condições inaptos e preguiçosos em outras palavras são os marginalizados dentro da escola. E essa constatação é proveitosa ao bancarismo, pois não almeja de forma alguma que os oprimidos assumam uma postura de desvelamento do mundo. Desse modo, Freire enfaticamente denuncia a postura de muitos educadores e nos faz pensar sobre o nosso papel: "Porque há um sem-número de educadores de boa vontade, que apenas não se sabem a serviço da desumanização ao praticarem o "bancarismo" (FREIRE, 2011, p.85).

Nessa altura, havia educadores(as) que demonstravam visivilmente estarem inquietos resultado das provocações. Nesse contexto, apresentamos então, o enfrentamento dessa perspectiva bancária pelo próprio Freire, a partir da caracterização da concepção pedagógica da Educação Problematizadora. Conforme Freire (2011), é necessário nesse processo para o educador, que, além dela buscar reconhecimento, a partir da constatação de que o processo formativo é um processo de humanização, partir das percepções das contradições das limitações da educação bancária e das formas de engajar-se pela libertação. Nesse sentido, muda radicalmente o papel do educador, pois,

Um educador humanista, revolucionário, não há de esperar possibilidade. Sua ação deve estar infundida da profunda crença nos homens no seu poder criador. Companheiro dos educando, em suas relações com eles (...) Saber com os educandos, enquanto estes soubessem com ele, seria sua tarefa. já não estaria a serviço da serviço da opressão, mas a serviço da libertação (FREIRE 2011, p.86-87).

O enfrentamento da bancarismo também aparece no papel que a educação problematizadora atribui à consciência. Isso relacionado ao papel que as elites dominadoras realizam no reforço dos processos alienantes faz com que, a educação não sendo neutra, esteja sempre a serviço de uma classe. Já uma população consciente enfrentará as condições de subserviência. Dessa forma, nos chama atenção, para o compromisso que temos enquanto 
educadores problematizadores: "Nosso objetivo é chamar a atenção dos verdadeiros humanistas para o fato de que eles não podem na busca da libertação, servir-se da concepção "bancária", sob pena de se contradizerem em sua busca" (FREIRE (2011, p.92).

Sugerindo e assumindo a partir da práxis como postura educativa na busca de transformar a realidade "a educação problematizadora coloca, desde logo, a exigência da superação da contradição educador-educandos" (FREIRE (2011, p.94). Por outro lado, aposta no diálogo como condição imprescindível para romper esse dualismo. A relação dialógica, permite-nos a compreensão de que o "O educador já não é o que apenas educa, mas o que , enquanto educa, é educado, em diálogo com o educando que, ao ser educado, também educa. Ambos assim, se tornam sujeitos do processo em que crescem juntos... FREIRE (2011,p.9596). E nesse contexto que aparece a compreensão coletiva do processo educativo descrito na tão citada frase de que "Os homens se educam em comunhão, mediatizados pelo mundo" (FREIRE (2011, p.96)

Nessa nova concepção, a educação assume se na condição de formação de sujeitos críticos, por que são dialógicos, sentem se desafiados a mudar o mundo com consciência sobre ele.

Finalizamos a reflexão nesse dia 29, reforçando aos educadores da EJA as "duas concepções, a "bancária", por óbvios motivos, insiste em manter, a problematizadora, comprometida com a libertação, a primeira nega o diálogo, enquanto que a segunda tem nele o selo do ato cognoscente, desvelador da realidade"(FREIRE (2011, p.101).

\section{Do acolhimento da Proposta}

É necessário reforçar, que tivemos inúmeros desdobramentos desse encontro para as ações futuras no contexto do Projeto Olhares-Sul-RioGrandenses da Educação de Jovens e Adultos. Algumas categorias emergiram dessas provocações iniciais:

1) Resistências;

2) Expectativas de Formação por palestras e síndrome da baixa estima e a dificuldade de assumir a condição de protagonista;

3) Assuncão da identidade problematizadora;

4) Eleição de temáticas geradoras;

5) Reivindicação da continuidade da formação

No que concerne as resistências, foi muito interessante perceber, que emergiram após esse momento. Começou um certo movimento oriundo das escolas. Chegavam até nós Revista Extensão em Foco, no 13, Jan/ Jul (2017) p. 23 - 35. 
expressões como: pra que formação na EJA? Estudar Paulo Freire pra que se já está superado? Além disso, havia sim o envolvimento com opções políticas, tanto no que se referia a SMEd, quanto a $18^{\mathrm{a}}$ Coordenadoria Regional de Educação. Sabíamos que tal movimento traria sim resistências. Também compreendíamos que era natural que houvesse, afinal estávamos "mexendo", problematizando saberes e práticas. Desse modo, como o curso ocorria em Núcleos, onde diversas escolas participavam percebemos em alguns desses núcleos algumas rejeições, acolhimentos e em alguns uma certa desesperança. No entanto, não havíamos nos dado conta, que também nós estávamos orientando a formação de uma maneira que consideramos depois equivocada.

No terceiro encontro, tivemos participação significativa numérica em todos os núcleos. No entanto num deles, eis que a resistência se manifesta. Chegamos a ser avisados sobre o descontentamento. Naquela noite tivemos grandes aprendizados na Escola Helena Small. Lá estavam mais de oitenta professores da EJA. Antes de começar a discussão sobre Narrativas em Rodas, realizamos com muita amorosidade talvez a conversa mais franca até aquele momento. Assim perguntamos inicialmente, sobre as motivações de estarmos ali naquele dia e horário. E sobre o sentido da formação para eles. Diversos educadores falaram. Um primeiro professor afirmou que não estavam gostando da metodologia. Ele preferia palestras.

Com essa afirmação foi respaldado por outros professores(as) que nos disseram: "vocês que vem da Universidade devem trazer soluções e novidades para nós". Outra educadora disse que estava cansada desse modelo de formação que a universidade vai até as escolas e depois escreve livros sobre eles. Outros se manifestaram a favor sobre como estava ocorrendo. Em especial, nos chamou atenção, a necessidade de que apresentássemos no estilo palestra. Recordamo-nos das práticas bancárias discutidas em encontros anteriores, onde o sujeito passivamente se comporta como objeto receptáculo. Damos-nos conta fundamentalmente, que nós também estávamos contribuindo com isso, pois não os tínhamos escutado. Isso mesmo! nós que defendemos a premissa freiriana de que ensinar exige saber escutar...

O forte impacto causado pelas constatações nas falas nos criou a necessidade de alternativas. Mas estávamos felizes, pois afinal estávamos realizando um diálogo sério e autêntico. Confessamos, que nos lembramos do diálogo de Freire com os camponeses, que afirmavam que Freire que era doutor é que sabiam e que eles não sabiam. Continuando as atividades, após uma longa escuta, continuamos a provocação contando narrativas sobre a obra da Prof. Dr ${ }^{\mathrm{a}}$ Cecília Warschauer referente às Narrativas em Roda. Após narrarmos a Revista Extensão em Foco, nº 13, Jan/ Jul (2017) p. 23 - 35. 
história da autora, trazendo a fecundidade da Roda, passamos a narrar histórias de vida. Lembro que a que eles (as) mais gostaram, era de um dos nossos educadores do Projeto Olhares, o Professor Sicero, que narrou como se alfabetizou e como no mesmo processo em seu mundo da vida, alfabetizou sua mãe. Eles (as) ficaram curiosos e queriam saber de quem se tratava. Emocionado o professor termina sua narrativa trazendo a revelação "aquele menino era eu".

Esse fato "mexeu muito com eles (as)" e havíamos criado o momento propício para Assumcão da identidade problematizadora. Solicitamos, que se alguém conhecesse alguma narrativa sua ou de um estudante da EJA, de sua escola ou comunidade e que se sentisse a vontade para narrar seria bem vindo (a). Na sequência ouvimos dez narrativas. Uma melhor que a outra. Belas narrativas, grávidas de vida, encharcadas de testemunhos e de sentidos. Este foi um encontro, em que tivemos dificuldades de encerrar, pela reivindicação permanente de participação. $\mathrm{O}$ resultado desse encontro reforçou o quanto as narrativas aproximama as pessoas e contribuem para que possam assumir seus protagonismos.

A partir desse encontro, éramos um grupo só no Projeto Olhares. Enquanto grupo de educadores populares, tínhamos a prática de nos reunir semanalmente para avaliar as aprendizagens que estávamos tendo com os professores e professoras. Tivemos na sequência mais um encontro no semestre. O objetivo era discutir avaliação no semestre posterior. Então, nessa perpectiva que reconhece avaliação enquanto processo, realizamos um Seminário para uma avaliação mais ampliada com todos os integrantes do projeto, além de aproveitarmos o espaço para apresentação de boas práticas vivenciadas na EJA.

Quando pensávamos que já tínhamos aprendido tudo, eis que no seminário de avaliação, vem a seguinte questão. "Vocês (FURG, SMEd, 18 ${ }^{\mathrm{a}} \mathrm{CRE}$ ) nos propuseram uma formação, mas, raramente nos pediram se queríamos e que se queríamos quais temáticas gostaríamos de debater na EJA além da avaliação". Perguntamos então: quais? e responderam: queremos conversar sobre: Avaliação sim, mas queremos conversar mais sobre Formação de Professores da EJA, Dependência Química na EJA, algo para nos cuidarmos pois os professores da EJA ficam muito na invisibilidade e necessitam de um olhar mais atento e de cuidado.

A partir dessa escuta planejamos todas as atividades para o ano posterior onde o Projeto Olhares enquanto projeto de extensão foi contemplado pelo segundo ano consecutivo (2013 e 2014). A última atividade do Projeto Olhares foi sobre a ética do cuidado e a cultura da paz. Todas as temáticas foram em atenção as escutas dos agora protagonistas da formação.

Revista Extensão em Foco, nº 13, Jan/ Jul (2017) p. 23 - 35. 


\section{CONSIDERAÇÕES FINAIS}

Os resultados desse movimento foram inúmeros e são imensuráveis na sua totalidade. A partir dos aprendizados e principalmente das escutas emergiram diversas questões que orientaram todo o trabalho no decorrer 2013 e 2014. A partir dessa concepção, houve um processo de identificação e de compromissos a serem assumidos na EJA no ccontexto do Projeto Olhares. Ficou reforçado, que trabalhar com essa modalidade de ensino pressupõe o olhar crítico e compromissado com a transformação da sociedade pela escola. Também foi constatado que essa proposta, pode contribuir no enfrentamento de uma modelo de escola, que já nas séries iniciais do ensino fundamental exclui crianças pelas formas seletivas e meritocráticas e que impedem muitos adultos a ter acesso a espaços na sociedade.

Igualmente relevante, é a constatação de que, a orientação epistemológica e metodológica, a partir da educação problematizadora, nos permitiu também discutir concepções de currículo, temas geradores e diversos encontros sobre avaliação, desde avaliação tradicional até a emancipadora. Isso permitiu inúmeras identificações que consequentemente tiveram decorrências práticas nas atuações futuras no contexto da sala de aula na EJA.

Outro aprendizado, é que devido a perspectiva dialética problematizadora, foi possível que mudássemos inúmeras atividades nos encontros presenciais com os educadores da EJA. Antes partíamos da exposição, posteriormente utilizamos a dialogicidade como elemento orientador de nossas práticas.

Ficou reforçado e continua sendo, que a perspectiva problematizadora amplia a nossa leitura de mundo e propicia novas aprendizagens. No início, tivemos muitas resistências, mas na atual conjuntura através do Projeto Olhares já podemos conceber a formação da EJA como permanente e como dimensão integrante da Rede Pública de Rio Grande, São José do Norte, Santa Vitória do Palmar e Chuí.

Em 2015 com o forte corte nas verbas da extensão impulsionada pela conjuntura política e econômica nacional a SECADI não abriu Edital EJA na diversidade e não estamos com o projeto em ação no entanto a rede continua com o processo. No entanto, tem sido muito relevante, em diferentes encontros onde temos a oportunidade de rever educadores que participaram do projeto emerge a seguinte reivindicação: quando voltarão com o Projeto Olhares? Nossa,satisfação, por termos saído de um cenário de invisibilidade de Formação na 
e com a EJA e em apenas dois anos de trabalho foi possível constatar, de que essa modalidade merece sim maior atenção e qualificação permanente.

Atualmente já publicamos um livro contando detalhamente essa história a partir de diferentes olhares e, além disso, estamos em fase de sistematização de um estudo que realizamos nesse universo sobre o Perfil do Educador e do Educando da EJA no contexto do Projeto Olhares.

Finalmente reforçamos, que a extensão crítica pode sim se constituir num espaço de emancipação de sujeitos. Para isso é fundamental transcender a noção de extensão como simples serviço ofertado a comunidade, mas fundamentalmente, como espaço de formação permanente, de valorização de saberes e reconhecimento de sujeitos.

\section{REFERÊNCIAS}

FREIRE, P. Pedagogia do Oprimido. 50 ed. Rio de Janeiro: Paz e Terra, 2011

FREIRE P. GADOTTI, M; GUIMARÃES Sérgio Pedagogia: diálogo e conflito. 6 ed. - São Paulo: Cortez, 2001. GADOTTI, M. História das idéias pedagógicas. 8. ed. São Paulo: Ática, 2002. $319 \mathrm{p}$.

GADOTTI, M. \& ROMÃO, J. E. Educação de Jovens e Adultos: teoria, prática e proposta. 8 ed. São Paulo Cortez, Instituto Paulo Freire, 2006.

PEREIRA, V. A. As inquietações que podem emergir quando a prática pedagógica é colocada à luz da reflexão. In: Claudemir de Quadros; Guacira de Azambuja. (Org.). Formação de professores em serviço: a experiência da Unifra. Santa Maria: Gráfica Editora Pallotti, 2002, v.1, p. 76-80.

A importância das teorias da Educação na formação do Educador. In: Corina MichelonDotti. (Org.). Educação: reflexões, vivências e pesquisa. 1. ed. Caxias do Sul: Editora da Universidade de Caxias do Sul, 2002, v. 01, p. 55-61.

; DIAS, J. R. L. ; TELMO . Educação Popular e a Pedagogia da Contra Marcha: uma homenagem a Gomercindo Ghiggi.. 1. ed. Passo Fundo: Méritos, 2013. v. 1.

(Org.) ; DORNELES, L.G (Org.) . Educação Popular no Contexto do PAIETS FURG: os Saberes da Pesquisa em Extensão Universitária. 1. ed. Porto Alegre: Evangraf, 2012.

(Org.) ; DORNELES, L.G (Org.) . Aprendizagens no Contexto do PET Conexões:

Revista Extensão em Foco, nº 13, Jan/ Jul (2017) p. 23 - 35. 
saberes da educação popular e saberes acadêmicos da FURG. 1. ed. Porto Alegre: Evangraf, 2012 .

(Org.) ; BORGES, D. S. (Org.) ; Neusiane Chaves de Souza (Org.) . Ventos que sopram no sul: vivências de educação popular e de transformação social no PAIETS-FURG.. 1. ed. Rio Grande: Editora da FURG, 2012.

(Org.) ; Zorzi (Org.) . Diálogos PROEJA: pluralidade, diferenças e vivências no sul do país. 1. ed. Porto Alegre: Evangraf, 2009.

(Org); MIRANDA. S.A (Org.). Olhares Sul-Riograndenses sobre Educação de Jovens e Adultos e a Educação Popular.. 1. ed. Passo Fundo: Méritos, 2016. 